\title{
The Effect of Simulated Auditory Hallucinations on Daily Activities in Schizophrenia Patients
}

\author{
Kiwan Han ${ }^{a}$ Jin-Kook Heo ${ }^{b}$ Seung-Ok Seo ${ }^{c}$ Mi-Yeon Hong ${ }^{c}$ Jung Suk Lee ${ }^{c}$ \\ Young Seok Shin ${ }^{d}$ Jeonghun Ku ${ }^{e}$ Sun I. Kim ${ }^{d}$ Jae-Jin Kim ${ }^{a-c}$ \\ ${ }^{a}$ Severance Biomedical Science Institute, ${ }^{b}$ Department of Psychiatry, and ${ }^{c}$ Institute of Behavioral Science in \\ Medicine, Yonsei University College of Medicine, and d Department of Biomedical Engineering, Hanyang University,

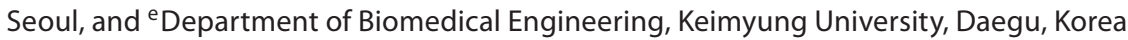

\section{Key Words}

Schizophrenia $\cdot$ Auditory hallucinations $\cdot$ Unusual voices •

Daily activities $\cdot$ Virtual reality

\begin{abstract}
Background: Auditory hallucinations often influence schizophrenia patients in many aspects. In order to develop effective behavioral interventions for overcoming enduring auditory hallucinations, it is necessary to understand how the annoying symptom affects the daily lives of the patients. This study evaluated the effect of hearing unusual voices on performing the activities of daily life in schizophrenia patients. Methods: Eighteen hallucinating patients, 18 nonhallucinating patients and 20 normal controls performed the virtual daily-life task of packing 8 items for travel under 3 conditions: (1) without unusual voices and without avatars, (2) with unusual voices and without avatars and (3) with unusual voices and with avatars. Task completion time and the number of times the packing list was checked were recorded as a measure of the task performance. Results: When exposed to unusual voices without avatars, hallucinating patients checked the packing list fewer times than nonhallucinating patients, and they required longer to complete the task, as
\end{abstract}

\section{KARGER}

Fax +4161306 1234

E-Mail karger@karger.ch

www.karger.com
(C) 2012 S. Karger AG, Basel

0254-4962/12/0456-0352\$38.00/0

Accessible online at:

www.karger.com/psp positive and negative symptoms were worse. Subjective responses to unusual voices were stronger in hallucinating patients than in nonhallucinating patients. Conclusions: Daily-life activities of hallucinating patients may be less easily influenced by odd auditory stimuli in a nonsocial situation than those of nonhallucinating patients; however, hallucinating patients may feel more strongly affected by unusual voices. To better evaluate and thereby understand the difficulties faced by hallucinating patients in their daily life, the discrepancies between objective and subjective measures as well as social situations should be taken into consideration.

Copyright $\odot 2012$ S. Karger AG, Basel

\section{Introduction}

Auditory hallucinations are a cardinal symptom of schizophrenia. Typically, patients hear one or more talking voices that no one else can hear, and these voices impact on many aspects of the daily lives of schizophrenia patients [1]. Over $60 \%$ of patients who experience auditory hallucinations are severely depressed and over $75 \%$ of them suffer from very high levels of distress [2]. About 
a quarter of schizophrenia patients experience command auditory hallucinations of suicide and one third of them attempt to commit suicide [3].

Schizophrenia patients have their own coping strategies including emotional and social aspects for overcoming difficulties induced by auditory hallucinations [4]. In order to develop effective interventions for coping with enduring auditory hallucinations, it is necessary to understand how the annoying symptom affects the daily lives of patients. However, investigation of the influences of auditory hallucinations on the daily lives of patients has relied solely on their subjective reports $[5,6]$. Because many schizophrenia patients have difficulty in describing their hallucinatory experiences, alternative measures should be taken to objectively evaluate responses to auditory hallucinations.

The virtual reality technique has been used successfully in psychiatric fields. For example, it has been used as an exposure tool during cognitive behavioral therapy for various phobia patients [7-9]. The authors of this study also reported that the technique was useful as an assisting tool for role-play exercises during social skills training [10] and for measuring interpersonal behaviors in schizophrenia patients [11]. The technique is particularly valuable in providing objective parameters for the evaluation of behavioral characteristics in various dailyliving environments $[12,13]$. In addition, an internetbased virtual reality system has been used for education on how to cope with hallucinations [14]. Therefore, based on a variety of previous applications, the authors expected that the virtual reality technique could be used to objectively evaluate the behavioral characteristics of hallucinating patients if auditory hallucinations were embodied as a form of unusual voices in a virtual environment.

It should be noted here that social situations need to be considered when conducting the evaluation. Previous studies have suggested that personal, interpretational and cognitive characteristics produce an effect on responses to auditory hallucinations [15-17]. Likewise, a social situation can affect the manifestations of auditory hallucinations; they lead to corresponding human behaviors and are related to changes in brain activity [18], and impairment in source monitoring is considered to be a pathophysiology of auditory hallucinations [19].

The purpose of this study was to evaluate the effect of unusual voices on the activities of daily life in schizophrenia patients. In order to obtain objective data of the daily living environment, we developed a virtual reality task in which unusual voices were used as simulated auditory hallucinations and a social situation was embodied by the presence or absence of avatars. In providing both hallucinating and nonhallucinating patients with this task, we addressed two issues regarding differences between the 2 groups: one was if hearing unusual voices affected task performance and the other was if there was a difference in subjective responses to these voices. We hypothesized that the impact of unusual voices on daily activities would be different according to the social situation, and that, compared to nonhallucinating patients, hallucinating patients would be less easily influenced by unusual voices because of their familiarity with auditory hallucinations.

\section{Methods}

\section{Participants}

Thirty-six schizophrenia patients and 20 normal controls [10 men and 10 women with a mean age of 28.9 years $(S D=6.0)$ and a mean education of 15.6 years $(\mathrm{SD}=2.6)$ ] participated in this study. Based on the endorsement of auditory hallucinations, patients were divided into 2 subgroups: 18 who were currently experiencing auditory hallucinations were assigned to the hallucinating group [11 men and 7 women with a mean age of 30.9 years $(\mathrm{SD}=6.1)$ and a mean education of 14.8 years $(\mathrm{SD}=6.2)]$, and 18 who had never experienced auditory hallucinations were assigned to the nonhallucinating group [12 men and 6 women with a mean age of 26.0 years $(S D=5.5)$ and a mean education of 14.2 years $(\mathrm{SD}=2.3)$. All patients were recruited from psychiatric outpatient clinics and the healthy controls were recruited from the local community. All participants were screened for psychiatric diagnoses using the Structured Clinical Interview for the DSM-IV (SCID-IV) [20] by a psychiatrist (J.-K.H.). Normal controls were eligible if they did not meet any criteria for psychiatric diagnoses. Participants with any present or previous medical or neurological illnesses related to cognitive, sensory and motor functions were excluded from this study. All participants provided written informed consent and the experimental protocol was approved by the local institutional review board.

\section{Experimental Setting and Task Procedure}

As presented in figure 1, the virtual daily-living task was to pack a few things for a trip. The virtual house, which comprised a bedroom, a living room, a kitchen and a bathroom, was displayed as a form of the egocentric view using a head-mounted display (HMD; eMagin Z800). The scenery continually changed in synchronization with head-movement data from the tracker (3DOF, intersence Intertrax 2), which was attached to the top of the participant's head. Participants could navigate the virtual house and execute their decisions using a joystick. The voice-recorded auditory stimuli were relayed via earphones.

Before beginning the virtual task, participants practiced getting used to the HMD and joystick for several minutes. Instructions for the task were then presented as a visual text and a voice. The first instruction informed participants of the final task objective, which was to find 8 target items on a packing list as quickly as possible. They were also informed of several tips, including 'Navigate the virtual house using the joystick to find the target 
Fig. 1. Composition of the virtual dailyliving task. a HMD, tracker, joystick and an earphone were used, which included scenes with/without avatars (b) and a packing list of the 8 target items (c). d Example of the task diagramming the presentation of the unusual voices that were either synchronized or not synchronized with a participant's behaviors. The figure also shows when an item was collected and when the packing list was viewed.
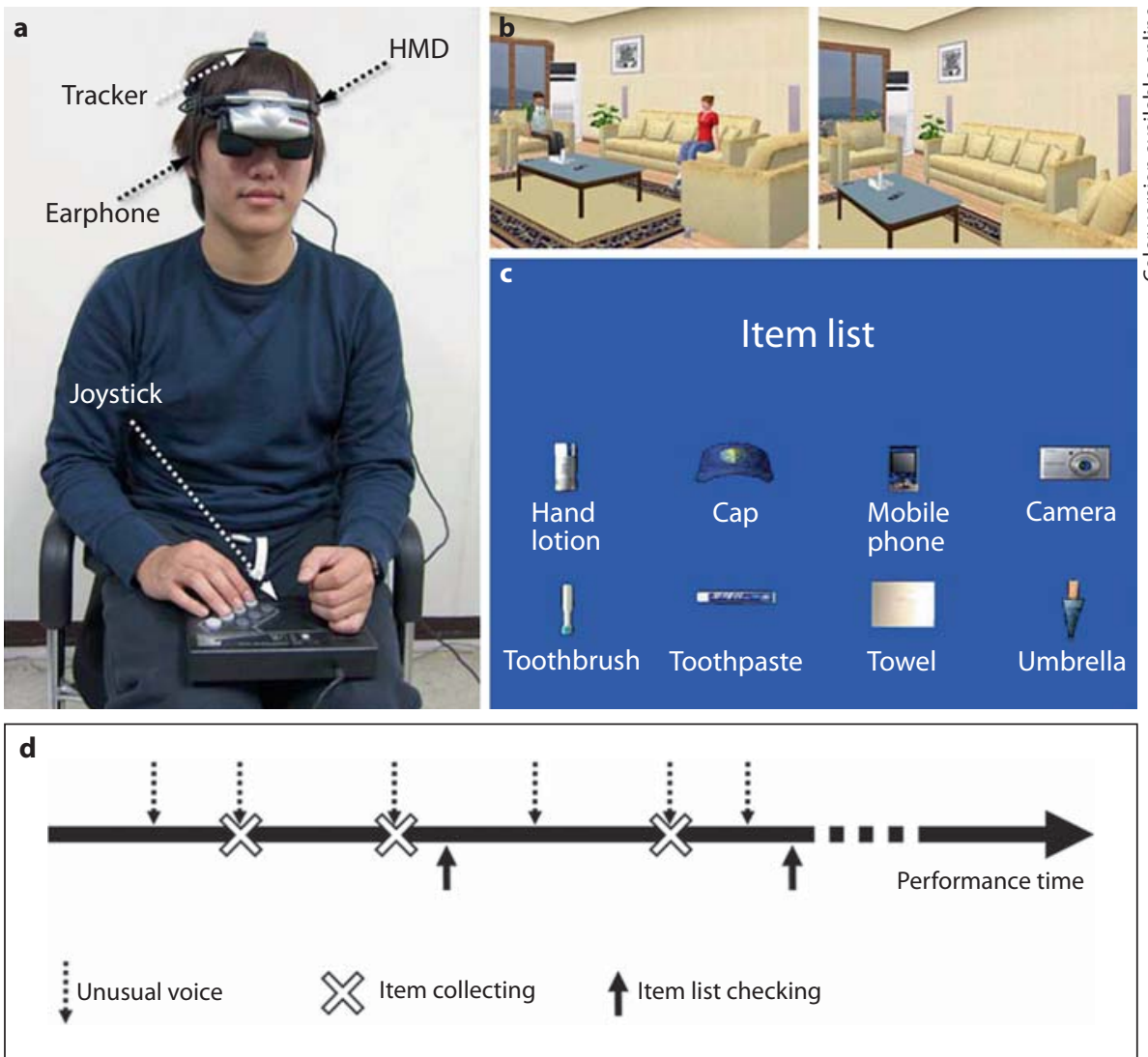

items' and 'Put the items into a suitcase using a joystick button upon finding them'. They were allowed to check the packing list using a joystick button whenever they did not recall it. When they had picked up all target items, the task was finished. The time taken to complete the task and the number of times that they checked the packing list were automatically recorded as a measure of the task performance.

Participants performed the task under different conditions: (1) in the absence of unusual voices and avatars, (2) in the presence of unusual voices and the absence of avatars and (3) in the presence of unusual voices and avatars. In the condition with unusual voices, verbal stimuli of a short duration of less than $3 \mathrm{~s}$ were presented 10-15 times, either in synchronization with the participant's behaviors or not. Content similar to the simulated auditory hallucinations of some previous studies was utilized [21, 22]: benevolent/neutral words (e.g. 'you are the one' or 'it will be okay'), derogatory terms (e.g. 'you suck' or 'loser'), paranoid comments (e.g. 'everyone is laughing at you') and action-related commands (e.g. 'stop it'). All of these had been ranked as 'heard frequently' in our preliminary survey for evaluating what auditory hallucinations schizophrenia patients experience. In the condition with the avatars, 4 avatars were presented in the virtual house: 1 was sitting on a chair in the bedroom, 2 were sitting on a sofa in the living room, and the other was standing in the kitchen. They did not speak or move while participants performed the task. The order of the 3 conditions was randomized among the participants, and a 10 -minute resting time was provided before going on to the next condition. On average, the entire experiment lasted 30-40 min.

\section{Assessment Instruments}

Before the experiment, cognitive ability was evaluated by Raven's Progressive Matrices (RPM) [23] and digit span. Compared with the normal control group, both patient groups showed lower cognitive ability when measured by RPM, but demonstrated equivocal ability when measured by digit span (table 1). Their clinical status was assessed using the Positive and Negative Syndrome Scale (PANSS) [24]. The 2 patient groups did not differ in positive-symptom subscale scores. In the analysis for each item, hallucinatory behavior scores were significantly higher in hallucinating patients than in nonhallucinating patients $(\mathrm{t}=3.57, \mathrm{p}<$ $0.01)$; however, there were no group differences in the scores of the other 6 items, including delusion. Negative-symptom subscale scores were significantly higher in hallucinating patients than in nonhallucinating patients $(\mathrm{t}=2.43, \mathrm{p}=0.02)$; however, there were no group differences in general-symptom subscale scores. Extrapyramidal side effects due to medication were monitored using the Barnes Akathisia Scale [25] and Simpson-Angus Scale [26]. The 2 patient groups did not differ in the level of extrapyramidal side effects or in the dose of antipsychotics.

After finishing the virtual task, participants were asked to answer questionnaires: the Simulator Sickness Questionnaire for 
Table 1. Demographic data of the hallucinating, nonhallucinating and normal control groups

\begin{tabular}{|c|c|c|c|c|c|}
\hline & & $\begin{array}{l}\text { H group } \\
(\mathrm{n}=18)\end{array}$ & $\begin{array}{l}\text { NH group } \\
(\mathrm{n}=18)\end{array}$ & $\begin{array}{l}\text { NCs } \\
(n=20)\end{array}$ & $\begin{array}{l}\text { Group comparisons } \\
\text { (post hoc) }\end{array}$ \\
\hline \multicolumn{2}{|l|}{ Male/female } & $11 / 7$ & $12 / 6$ & $10 / 10$ & $\mathrm{H}=\mathrm{NH}=\mathrm{NC}$ \\
\hline \multicolumn{2}{|l|}{ Age, years } & $30.9(6.1)$ & $26.0(5.5)$ & $28.9(6.0)$ & $\mathrm{H}>\mathrm{NH}=\mathrm{NC}^{*}$ \\
\hline \multicolumn{2}{|l|}{ Education, years } & $14.8(6.2)$ & $14.2(2.3)$ & $15.6(2.6)$ & $\mathrm{H}=\mathrm{NH}=\mathrm{NC}$ \\
\hline \multicolumn{2}{|l|}{ RPM } & $45.5(8.6)$ & $46.4(7.2)$ & $52.8(4.0)$ & $\mathrm{H}=\mathrm{NH}<\mathrm{NC}^{* *}$ \\
\hline \multirow{3}{*}{ PANSS } & negative & $14.1(5.5)$ & $10.6(2.8)$ & & $\mathrm{H}>\mathrm{NH}^{*}$ \\
\hline & general & $29.8(8.9)$ & $26.2(8.3)$ & & $\mathrm{H}=\mathrm{NH}$ \\
\hline & total & $59.3(17.3)$ & $51.2(15.3)$ & & $\mathrm{H}=\mathrm{NH}$ \\
\hline \multicolumn{2}{|l|}{ BAS } & $0.2(0.4)$ & $0.2(0.4)$ & & $\mathrm{H}=\mathrm{NH}$ \\
\hline \multicolumn{2}{|l|}{ SAS } & $0.1(0.1)$ & $0.1(0.2)$ & & $\mathrm{H}=\mathrm{NH}$ \\
\hline \multicolumn{6}{|c|}{ Doses of antipsychotics, mg } \\
\hline
\end{tabular}

Values are shown as mean $(\mathrm{SD}) .{ }^{*} \mathrm{p}<0.05 ;{ }^{*} \mathrm{p}<0.01$.

$\mathrm{BAS}=$ Barnes akathisia scale; $\mathrm{H}=$ hallucinating; $\mathrm{NC}=$ normal control; $\mathrm{NH}=$ nonhallucinating; $\mathrm{RPM}=\mathrm{Raven}$ 's progressive matrices; $\mathrm{SAS}=$ Simpson-Angus scale.

Table 2. Comparisons of the mean responses of the hallucinating, nonhallucinating and normal control groups on the VREQ

\begin{tabular}{|c|c|c|c|c|}
\hline & $\begin{array}{l}\text { H group } \\
(\mathrm{n}=18)\end{array}$ & $\begin{array}{l}\text { NH group } \\
(\mathrm{n}=18)\end{array}$ & $\begin{array}{l}\text { NCs } \\
(n=20)\end{array}$ & $\begin{array}{l}\text { Group } \\
\text { comparisons } \\
\text { (post hoc) }\end{array}$ \\
\hline 1. How easily could you ignore the unusual voices? & $2.4(1.2)$ & $2.9(1.0)$ & $3.5(0.8)$ & $\mathrm{H}<\mathrm{NH}=\mathrm{NC}^{* *}$ \\
\hline 2. How much did the unusual voices interfere with you collecting the travel items? & $2.1(0.9)$ & $1.6(0.6)$ & $1.4(0.6)$ & $\mathrm{H}>\mathrm{NH}=\mathrm{NC}^{*}$ \\
\hline 3. How difficult was it to use the control devices? & $2.2(1.0)$ & $2.1(0.9)$ & $2.1(0.9)$ & $\mathrm{H}=\mathrm{NH}=\mathrm{NC}$ \\
\hline 4. How inconvenient was it to perform the virtual task? & $3.3(0.7)$ & $2.8(0.8)$ & $3.2(0.8)$ & $\mathrm{H}=\mathrm{NH}=\mathrm{NC}$ \\
\hline 5. How uncomfortable did you feel while looking around the virtual house? & $2.6(1.1)$ & $2.1(0.8)$ & $2.6(0.8)$ & $\mathrm{H}=\mathrm{NH}=\mathrm{NC}$ \\
\hline 6. How clearly did you hear the unusual voices? & $3.0(1.1)$ & $3.2(0.8)$ & $3.6(0.6)$ & $\mathrm{H}=\mathrm{NH}=\mathrm{NC}$ \\
\hline
\end{tabular}

Values are shown as mean (SD) for Likert scales $\left(1=\right.$ not at all, $4=$ very much). ${ }^{*} \mathrm{p}<0.05 ;{ }^{*} \mathrm{p}<0.01$.

$\mathrm{H}=$ Hallucinating; $\mathrm{NC}=$ normal control; $\mathrm{NH}=$ nonhallucinating.

subjective evaluation of simulator sickness [27] and the Presence Questionnaire for measuring how participants were immersed and focused on the virtual environment [28]. They were also asked to answer the Virtual Reality Experience Questionnaire (VREQ) that we developed for this experiment to evaluate responses to the unusual voices and the ease of performing a task in the virtual environment. As shown in table 2, the VREQ was composed of 6 questions and 4-point Likert responses $(1=$ not at all, 4 = very much).

\section{Data Analysis}

One-way ANOVA was used to test differences between groups in the task completion time and the number of times the packing list was checked across the 3 task conditions. It was also used to test differences in answers to the post-task questionnaires. The Bonferroni test was used for post hoc analyses when a significant difference was found. In order to compare differences between the conditions, repeated measures ANOVA was done. Because there was no condition for the absence of unusual voices and presence of avatars in the study design, 2 separate analyses were conducted: to test for the main effect of either the presence of unusual voices or of avatars and the interaction of these effects with the group. In order to evaluate the effect of the symptom severity, Pearson correlation analyses were performed to correlate the performance of the virtual task with the subtotal and total scores of the PANSS in each patient group. 
Table 3. Comparisons of virtual task performance and post-task questionnaires among the hallucinating, nonhallucinating and normal control groups

\begin{tabular}{|c|c|c|c|c|}
\hline & $\begin{array}{l}\text { H group } \\
(\mathrm{n}=18)\end{array}$ & $\begin{array}{l}\text { NH group } \\
(\mathrm{n}=18)\end{array}$ & $\begin{array}{l}\text { NCs } \\
(n=20)\end{array}$ & $\begin{array}{l}\text { Group } \\
\text { comparisons (post hoc) }\end{array}$ \\
\hline \multicolumn{5}{|l|}{ Task completion time, $s$} \\
\hline Without unusual voices and without avatars & $357.3(172.7)$ & $368.1(93.8)$ & $229.0(94.9)$ & $\mathrm{H}=\mathrm{NH}>\mathrm{NC}^{* *}$ \\
\hline With unusual voices and without avatars & $326.1(120.3)$ & $322.5(109.3)$ & $262.0(80.3)$ & $\mathrm{H}=\mathrm{NH}=\mathrm{NC}$ \\
\hline With unusual voices and with avatars & $294.0(135.8)$ & $258.7(104.0)$ & $224.2(89.1)$ & $\mathrm{H}=\mathrm{NH}=\mathrm{NC}$ \\
\hline \multicolumn{5}{|l|}{ Number of times packing list was checked } \\
\hline Without unusual voices and without avatars & $5.2(2.7)$ & $7.1(3.5)$ & $2.0(1.2)$ & $\mathrm{H}=\mathrm{NH}>\mathrm{NC}^{* *}$ \\
\hline With unusual voices and without avatars & $4.1(2.2)$ & $5.7(1.8)$ & $2.0(0.8)$ & $\mathrm{NH}>\mathrm{H}>\mathrm{NC}^{* *}$ \\
\hline With unusual voices and with avatars & $4.2(2.6)$ & $5.1(2.8)$ & $1.8(0.8)$ & $\mathrm{H}=\mathrm{NH}>\mathrm{NC}^{* *}$ \\
\hline Simulation Sickness Questionnaire & $27.3(9.5)$ & $25.9(8.7)$ & $24.9(9.5)$ & $\mathrm{H}=\mathrm{NH}=\mathrm{NC}$ \\
\hline Presence Questionnaire & $62.0(11.2)$ & $52.6(9.8)$ & $58.2(7.3)$ & $\mathrm{H}>\mathrm{NH}=\mathrm{NC}^{*}$ \\
\hline
\end{tabular}

Values are shown as mean (SD). ${ }^{*} \mathrm{p}<0.05 ;{ }^{* *} \mathrm{p}<0.01$

$\mathrm{H}=$ Hallucinating; $\mathrm{NC}=$ normal control; $\mathrm{NH}=$ nonhallucinating.

\section{Results}

\section{Task Completion Time}

As shown in table 3 , the 3 groups showed significantly different task completion times for the condition without unusual voices and avatars $\left(\mathrm{F}_{[2,53]}=7.39, \mathrm{p}<0.01\right)$. Both patient groups completed the task more slowly than the

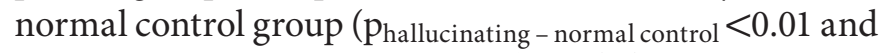

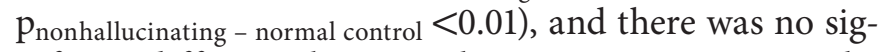
nificant difference between the 2 patient groups. On the other hand, the 3 groups did not show significantly different task completion times for the other 2 conditions. In repeated-measures ANOVA, the presence of unusual voices showed no significant main effect and interaction with the group, while the presence of avatars showed a significant main effect $\left(\mathrm{F}_{[2,1]}=9.36, \mathrm{p}<0.01\right)$ but no significant interaction with the group.

\section{Number of Packing List Checks}

The 3 groups demonstrated significant differences in the number of times they checked the packing list under all 3 conditions $\left(\mathrm{F}_{[2,53]}\right.$ without unusual voices and without avatars $=$ 18.78, $\mathrm{p}<0.01 ; \mathrm{F}_{[2,53]}$ with unusual voices and without avatars $=$ $23.50, \mathrm{p}<0.01 ; \mathrm{F}_{[2,53]}$ with unusual voices and with avatars $=11.73$, $\mathrm{p}<0.01)$. Under the condition without unusual voices and avatars, both patient groups checked the packing list more times than the normal control group ( $\mathrm{p}_{\text {hallucinating - }}$ normal control $<0.01$ and pnonhallucinating - normal control $<0.01$ ), and there was no difference between the 2 patient groups. Under the condition with unusual voices and without avatars, the nonhallucinating group checked the list more times than the hallucinating and normal control groups, and the hallucinating group checked the list more times than the normal control group ( $\mathrm{p}_{\text {nonhallucinating - hallucinating }}$

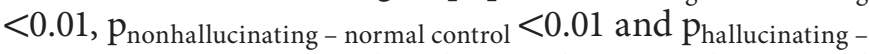
normal control $<0.01)$. Under the condition with unusual voice and avatars, the pattern of differences in the number of packing list checks among the 3 groups was the same as that under the condition without unusual voices and avatars. In repeated-measures ANOVA, the presence of unusual voices showed a significant main effect $\left(\mathrm{F}_{[2,1]}=14.58, \mathrm{p}<0.01\right)$ and interaction with the group $\left(\mathrm{F}_{[2,1]}=4.06, \mathrm{p}=0.02\right)$, but the presence of avatars showed no significant main effect orinteraction with the group.

\section{Group Differences in the Questionnaires}

The 3 groups showed no difference in Simulator Sickness Questionnaire scores, but a significant difference in Presence Questionnaire scores $\left(\mathrm{F}_{[2,53]}=4.45, \mathrm{p}=0.02\right.$; a significant difference was found only between the hallucinating and nonhallucinating groups). In the case of the VREQ, compared to the nonhallucinating and normal control groups, the hallucinating group reportedly felt that it was more difficult to ignore the unusual voices $\left(\mathrm{F}_{[2,53] \text { item } 1}=5.35, \mathrm{p}<0.01\right)$ and was more disturbed by the unusual voices $\left(\mathrm{F}_{[2,53]}\right.$ item $\left.2=4.92, \mathrm{p}=0.01\right)$. However, the 3 groups did not show significant differences in the other items of the VREQ, indicating that both patient groups controlled the devices, performed the virtual task, navigated in the virtual environment and perceived the unusual voices as easily as the normal controls. 


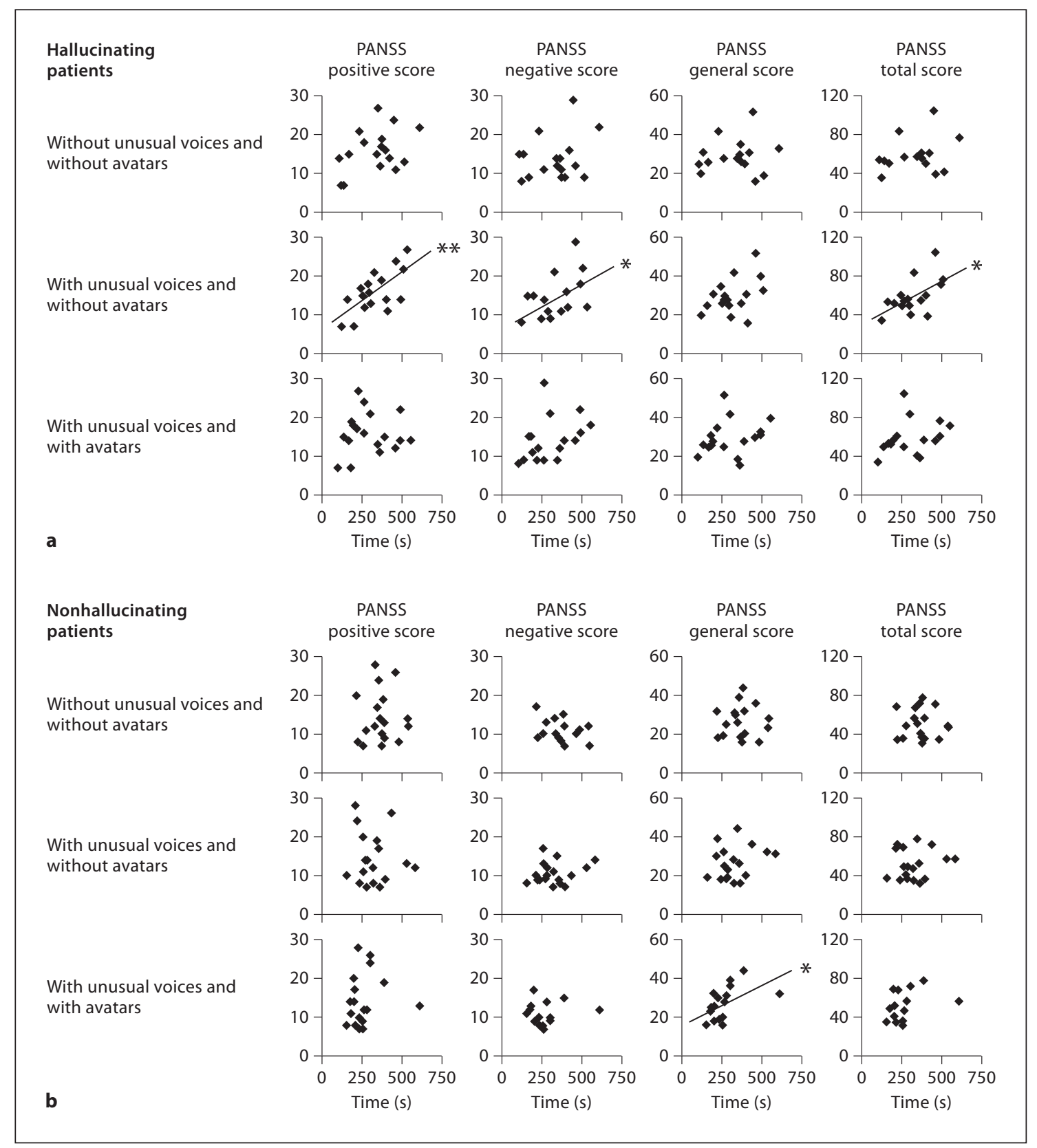

Fig. 2. Correlations between the PANSS and the task completion time in schizophrenia patients with (a) or without (b) auditory hallucinations under 3 different conditions. ${ }^{*} \mathrm{p}<0.05 ;{ }^{* *} \mathrm{p}<0.01$.

Correlation of the Task Performance with the

Symptom Severity

The hallucinating group showed a significant correlation of the task completion time with PANSS scores $\left(\mathrm{r}_{\text {positive }}=0.67, \mathrm{p}<0.01 ; \mathrm{r}_{\text {negative }}=0.50, \mathrm{p}=0.03 ; \mathrm{r}_{\text {general }}=\right.$ $\left.0.44, \mathrm{p}=0.07 ; \mathrm{r}_{\text {total }}=0.58, \mathrm{p}=0.01\right)$ only under the condition with unusual voices and without avatars (fig. 2a). In the nonhallucinating group, the only significant correlation of the task completion time with PANSS scores was found with general scores in the condition with unusual voices and avatars $(r=0.52, p=0.03$; fig. $2 b)$. In contrast, there were no significant correlations between the number of packing list checks and PANSS scores in either patient group. 


\section{Discussion}

In this study, the ability of participants with schizophrenia to perform daily-living activities in a virtual environment was tested. Participants performed task-related behaviors (navigation and search) to achieve a goal (packing for a trip) while exposed to unusual voices and social situations. The first issue raised was whether or not the effect of hearing unusual voices on the performance of the task (i.e. on the time taken to complete the task and the number of times the packing list was checked) would be different between hallucinating and nonhallucinating patients. The results revealed no difference between the groups for task completion time, only for the number of times the packing list was checked; as expected, this difference was revealed to depend on a social situation. In this study, hallucinating patients checked the packing list less times than nonhallucinating patients when unusual voices were present without avatars, but not when they were present with avatars. This seemed to result from a difference in the familiarity with hallucinatory voices. When external sensory stimuli such as unusual voices are perceived, people can usually attribute them to voice-related contextual cues to reduce uncertainty and to improve efficiency in performing the activities of daily life [29]. When avatars were present, both hallucinating and nonhallucinating patients might easily have attributed unusual voices to the avatars. On the other hand, when no avatars were present, both hallucinating and nonhallucinating patients might have had difficulty in attributing unusual voices to an external cause. Because hallucinating patients are used to hearing hallucinatory voices even when they are alone, the condition without avatars appeared less strange for them than for the nonhallucinating patients; this familiarity with hallucinations may be also be a reason why they performed better than the nonhallucinating patients. In the situation with unusual voices and without avatars, remembering target items was more interfered with in nonhallucinating patients than in hallucinating patients.

Although the condition with unusual voices and without avatars was more familiar to hallucinating patients than nonhallucinating patients, this situation still seemed to be more stressful to hallucinating patients than the other conditions were. The task completion time in hallucinating patients was positively correlated with symptom severity only when unusual voices were heard without avatars. This feature may also stem from a difference in source attribution for each condition. When difficulty in attributing unusual voices to an ex- ternal cause was encountered under the condition without avatars, hallucinating patients could equate the unusual voices with their own hallucinatory voices. This could be the reason why task completion was influenced in hallucinating patients by symptom severity only when unusual voices were present in a nonsocial situation. Schizophrenia patients describe auditory hallucinations as sounding like real voices [30], but often experience difficulty in localizing their source [31, 32]. Schizophrenia patients also tend to perceive internal speech as coming from an external source [33-35]. Because of these characteristics, hallucinating patients in this study might have been confused when there was no possible agent to whom to attribute the unusual vocal stimuli. This confusion can induce distress and loss of control when hearing unusual voices, and it can interfere with appropriate coping strategies [36]. This interpretation is inconclusive, however, because during the experiment we did not ask the participants to what or to whom they attributed the unusual voices.

The second issue was whether or not there was a difference in subjective responses to unusual voices between the 2 patient groups. As shown in the results from the VREQ, hallucinating patients demonstrated the ability to ignore the unusual voices to a lesser degree and experienced more interference from the unusual voices than the nonhallucinating patients. This suggests that subjective responses to the unusual voices were stronger in hallucinating patients than in nonhallucinating patients. These responses are contradictory to the results from the number of times the packing list was checked as an objective measure. This discrepancy revealed that there could be a considerable gap between subjective experiences and real performances in hallucinating patients.

Hallucinating patients reported higher scores in the Presence Questionnaire than the nonhallucinating group, suggesting that the former - familiar with hearing unusual voices - were easily immersed in the virtual environment. Presence is defined as a participant's sense of 'being there' in the virtual environment [37] and occurs when a participant forgets that his/her perceptions are mediated by technology [38]. Higher presence indicates that a user perceives the virtual environment as real and that his/her sensations and actions are responsive to the virtual world as if it were the real world [38-44]. Therefore, stronger subjective responses to virtual stimuli in hallucinating patients may have been related to higher presence. Given that the subjective experience of virtual reality can impact on the effectiveness of virtual treat- 
ments [10, 45], our findings indicate that the virtual task can be used in cognitive behavioral training to control auditory hallucinations.

There are some limitations to this study. First, despite efforts to balance demographic factors among the 3 groups, the hallucinating group was older than the other 2 groups. Because there was no difference between the 2 patient groups in education and cognitive ability as assessed by the RPM and digit span, a difference in age seemed less likely to affect the task performance. Second, the contents of the unusual voices in this study were composed similarly to that of common auditory hallucinations, so that the unusual voices mimicked auditory hallucinations. However, this was not verified by participants in the experiment. Third, the condition for the absence of unusual voices and the presence of avatars was not included in the study design. Although this was done to reduce the running time, it was problematic that we did not have data on the performance in a social situation without unusual voices. Fourth, the daily-living activities in this experiment were confined to packing travel items at home, and thus generalizations on the behavioral characteristics of other daily activities should be made with caution. For instance, different behaviors might have occurred if the task were an interpersonal activity. Finally, performance was measured according to only 2 parameters, the task completion time and the number of pack- ing list checks. In order to reflect the real activities that make up daily life, a variety of task parameters should be included such as gaze pattern or behavioral change after auditory stimuli.

\section{Conclusions}

We developed the virtual daily-living task to assess the performance of daily activities, and used this task to measure the effect of unusual voices on the ability of schizophrenia patients to complete a common task. Schizophrenia patients with auditory hallucinations were less influenced by unusual voices in performing the task under the nonsocial condition without avatars; however, they felt more strongly affected by unusual voices. To better evaluate and thereby understand the difficulties faced by hallucinating patients in the context of their daily life and during behavioral training, discrepancies between objective and subjective measures as well as social situations should be taken into consideration.

\section{Acknowledgement}

This study was supported by a grant from the Korea Health 21 R\&D Project, Ministry of Health, Welfare and Family, Republic of Korea (A090537).

\section{References}

1 Heinrichs DW, Carpenter WT: Prospective study of prodromal symptoms in schizophrenic relapse. Am J Psychiatry 1985;142: 371-373.

2 Birchwood M, Meaden A, Trower P, Gilbert P, Plaistow J: The power and omnipotence of voices: subordination and entrapment by voices and significant others. Psychol Med 2000;30:337-344.

3 Harkavy-Friedman JM, Kimhy D, Nelson EA, Venarde DF, Malaspina D, Mann JJ: Suicide attempts in schizophrenia: the role of command auditory hallucinations for suicide. J Clin Psychiatry 2003;64:871-874.

-4 Bak M, van der Spil F, Gunther N, Radstake S, Delespaul P, van Os J: Maastricht Assessment of Coping Strategies (MACS-I): a brief instrument to assess coping with psychotic symptoms. Acta Psychiatr Scand 2001;103: 453-459.

5 Chadwick P, Birchwood M: The omnipotence of voices. II: The Beliefs About Voices Questionnaire (BAVQ). Br J Psychiatry 1995; 166:773-776.

The Effect of Unusual Voices on Daily Activities in Schizophrenia

Activities in Schizophrenia
6 Sanjuan J, Gonzalez JC, Aguilar EJ, Leal C, van Os J: Pleasurable auditory hallucinations. Acta Psychiatr Scand 2004;110:273278.

7 Walshe DG, Lewis EJ, Kim SI, O’Sullivan K, Wiederhold BK: Exploring the use of computer games and virtual reality in exposure therapy for fear of driving following a motor vehicle accident. Cyberpsychol Behav 2003; 6:329-334.

-8 Jang DP, Ku JH, Choi YH, Wiederhold BK, Nam SW, Kim IY, Kim SI: The development of virtual reality therapy (VRT) system for the treatment of acrophobia and therapeutic case. IEEE Trans Inf Technol Biomed 2002; 6:213-217.

$\checkmark 9$ da Costa RM, de Carvalho LA: The acceptance of virtual reality devices for cognitive rehabilitation: a report of positive results with schizophrenia. Comput Methods Programs Biomed 2004;73:173-182.
10 Park KM, Ku J, Choi SH, Jang HJ, Park JY, Kim SI, Kim JJ: A virtual reality application in role-plays of social skills training for schizophrenia: a randomized, controlled trial. Psychiatry Res 2011;189:166-172.

11 Park SH, Ku J, Kim JJ, Jang HJ, Kim SY, Kim $\mathrm{SH}$, Kim CH, Lee H, Kim IY, Kim SI: Increased personal space of patients with schizophrenia in a virtual social environment. Psychiatry Res 2009;169:197-202.

12 Han K, Ku J, Kim K, Jang HJ, Park J, Kim J, Kim CH, Choi M, Kim IY, Kim SI: Virtual reality prototype for measurement of expression characteristics in emotional situations. Comput Biol Med 2009;39:173-179.

13 Lee JH, Ku J, Cho W, Hahn WY, Kim IY, Lee SM, Kang Y, Kim DY, Yu T, Wiederhold BK, Wiederhold MD, Kim SI: A virtual reality system for the assessment and rehabilitation of the activities of daily living. Cyberpsychol Behav 2003;6:383-388.

14 Yellowlees PM, Cook JN: Education about hallucinations using an internet virtual reality system: a qualitative survey. Acad Psychiatry 2006;30:534-539. 
15 Lung FW, Shu BC, Chen PF: Personality and emotional response in schizophrenics with persistent auditory hallucination. Eur Psychiatry 2009;24:470-475.

- 16 Morrison AP, Nothard S, Bowe SE, Wells A: Interpretations of voices in patients with hallucinations and non-patient controls: a comparison and predictors of distress in patients. Behav Res Ther 2004;42:1315-1323.

-17 Stinson K, Valmaggia LR, Antley A, Slater M, Freeman D: Cognitive triggers of auditory hallucinations: an experimental investigation. J Behav Ther Exp Psychiatry 2010;41: 179-184.

18 Morris JP, Pelphrey KA, Mccarthy G: Regional brain activation evoked when approaching a virtual human on a virtual walk. J Cogn Neurosci 2005;17:1744-1752.

-19 Brunelin J, Combris M, Poulet E, Kallel L, D’Amato T, Dalery J, Saoud M: Source monitoring deficits in hallucinating compared to non-hallucinating patients with schizophrenia. Eur Psychiatry 2006;21:259-261.

-20 Spitzer RL, Williams JB, Gibbon M, First MB: The structured clinical interview for DSM-III-R (SCID): history, validation, and description. Arch Gen Psychiatry 1992;49: 624-629.

21 Brown SA: Implementing a brief hallucination simulation as a mental illness stigma reduction strategy. Community Ment Health J 2010;46:500-504.

22 Bunn W, Terpstra J: Cultivating empathy for the mentally ill using simulated auditory hallucinations. Acad Psychiatry 2009;33: 457-460.

23 Raven J: Manual for Raven's Progressive Matrices and Vocabulary Scales: general overview section 1. Oxford, Oxford Psychologists Press, 1993.
24 Kay S, Fiszbein A, Opler L: The positive and negative syndrome scale (PANSS) for schizophrenia. Schizophr Bull 1987;13:261-276.

-25 Barnes TR: A rating scale for drug-induced akathisia. Br J Psychiatry 1989;154:672-676.

-26 Simpson GM, Angus JW: A rating scale for extrapyramidal side effects. Acta Psychiatr Scand 1970;45:11-19.

-27 Kennedy RS, Lilienthal MG, Berbaum KS, Baltzley DR, McCauley ME: Simulator sickness in U.S. Navy flight simulators. Aviat Space Environ Med 1989;60:10-16.

28 Stanney K, Salvendy G, Deisinger J, DiZio P, Ellis S, Ellison J, Fogleman G, Gallimore J, Hettinger L, Kennedy R, Lackner J, Lawson B, Maida J, Mead A, Mon-Williams M, Newman D, Piantanida T, Reeves L, Riedel O, Singer M, Stoffregen T, Wann J, Welch R, Wilson J, Witmer B: After effects and sense of presence in virtual environments: formulation of a research and development agenda. Int J Hum Comput Interact 1998;10:135-187.

29 de Gelder B, Vroomen J, Annen L, Masthof E, Hodiamont P: Audio-visual integration in schizophrenia. Schizophr Res 2003;59:211218.

30 Garrett M, Silva R: Auditory hallucinations, source monitoring, and the belief that 'voices' are real. Schizophr Bull 2003;29:445-457.

31 Junginger J, Frame CL: Self-report of the frequency and phenomenology of verbal hallucinations. J Nerv Ment Dis 1985;173:149155.

32 Nayani TH, David AS: The auditory hallucination: a phenomenological survey. Psychol Med 1996;26:177-189.

33 Ditman T, Kuperberg GR: A source-monitoring account of auditory verbal hallucinations in patients with schizophrenia. Harv Rev Psychiatry 2005;13:280-299.

34 Hoffman R: Verbal hallucinations and language production processes in schizophrenia. Behav Brain Sci 1986;9:503-517.
35 Morrison A, Haddock G, Tarrier N: Intrusive thoughts and auditory hallucinations: a cognitive approach. Behav Cogn Psychother 1995;23:265-280.

-36 Jenner JA, Nienhuis FJ, Wiersma D, van de Willige G: Hallucination focused integrative treatment: a randomized controlled trial. Schizophr Bull 2004;30:133-145.

37 Barfield W, Zeltzer D, Sheridan TB, Slater M: Virtual Environments and Advance Interface Design. London, Oxford University Press, 1995.

38 Lombard M, Ditton T: At the heart of it all: the concept of presence. J Comput Mediat Commun 1997. http://www.ascusc.org/ $\mathrm{jcmc/vol3/issue2/lombard.htm} \mathrm{(accessed}$ April 29, 2004).

39 Biocca F, Harms C, Burgoon J: Toward a more robust theory and measure of social presence: review and suggested criteria. Presence-Teleop Virt 2003;12:456-480.

40 Lee KM: Presence, explicated. Commun Theory 2004; 14:27-50.

41 Loomis JM: Presence and distal attribution: phenomenology, determinants, and assessment. Proc SPIE 1992;1666:590-595.

42 Slater M, Steed A: A virtual presence counter. Presence-Teleop Virt 2000;9:413-434.

43 Steuer J: Defining virtual reality: Dimensions determining telepresence. J Commun 1992;42:73-93.

44 Witmer B, Singer M: Measuring presence in virtual environments: a presence questionnaire. Presence-Teleop Virt 1998;7:225-240.

45 Krijn M, Emmelkamp PM, Biemond R, de Wilde de Ligny C, Schuemie MJ, van der Mast CA: Treatment of acrophobia in virtual reality: the role of immersion and presence. Behav Res Ther 2004;42:229-239. 